\title{
What is new in pediatric cardiac imaging?
}

\author{
Luc Mertens • Javier Ganame • Bénédicte Eyskens
}

Received: 8 March 2007 / Accepted: 6 June 2007 / Published online: 10 July 2007

(C) Springer-Verlag 2007

\begin{abstract}
Cardiac imaging has had significant influence on the science and practice of pediatric cardiology. Especially the development and improvements made in noninasive imaging techniques, like echocardiography and cardiac magnetic resonance imaging (MRI), have been extremely important. Technical advancements in the field of medical imaging are quickly being made. This review will focus on some of the important evolutions in pediatric cardiac imaging. Techniques such as intracardiac echocardiography, 3D echocardiography, and tissue Doppler imaging are relatively new echocardiographic techniques, which further optimize the anatomical and functional aspects of congenital heart disease. Also, the current standing of cardiac MRI and cardiac computerized tomography will be discussed. Finally, the recent European efforts to organize training and accreditation in pediatric echocardiography are highlighted.
\end{abstract}

Keywords Cardiac imaging · Echocardiography · Magnetic resonance imaging $\cdot \mathrm{CT}$ Scan

\section{How imaging changed the face of pediatric cardiology}

One of the technical revolutions which changed the face and practice of pediatric cardiology, undoubtedly, was the development of noninvasive imaging techniques. Until about 40 years ago, clinicians could only vaguely imagine how the heart of their patients anatomically and functionally looked. It was the stethoscope, the ECG and the chest

L. Mertens $(\bowtie) \cdot J$. Ganame $\cdot$ B. Eyskens

Pediatric Cardiology, University Hospitals Leuven,

Herestraat 49,

3000 Leuven, Belgium

e-mail: luc.mertens@uzleuven.be
X-ray which guided the clinician to pediatric heart disease, and the clinical skills were at the 'heart' of the profession. The development of cardiac catheterization and angiography in the 1960s and echocardiography in the 1980s profoundly changed the face of pediatric cardiology. Cardiac catherization was the first technique which allowed imaging of the heart and extracardiac vessels by angiography. In addition, pressures can be directly measured and intracardiac shunts can be calculated. It is, however, an invasive procedure involving radiation and can be associated with complications [6]. Cardiac ultrasound is a noninvasive technique allowing anatomy assessment, valvular function, as well as ventricular systolic and diastolic function $[12,42]$. Initially the main developments in pediatric echocardiography were focussed on describing cardiac anatomy by 2D images. During the 1980 s there were a very large number of publications describing the echocardiographic-morphological correlations resulting from a close collaboration between cardiac morphologists and pediatric cardiologists. In this era the different congenital lesions were described in detail and this contributed, to a large extent, to better treatment and outcome for patients. The additional development of Doppler techniques, which allowed visualization and quantifying of blood pool velocities, were extremely important for the increased accuracy in the diagnosis of pediatric heart disease. The 'echolab' has become a true morphologic and hemodynamic laboratory and transthoracic echocardiography has become the 'working horse' of pediatric cardiology. It has replaced cardiac catheterization for a large number of congenital abnormalities. Currently a lot of congenital lesions are referred directly to the surgeon for interventional catheterization based on an echocardiographic diagnosis only. These include lesions like atrial septal defects, ventricular septal defects, atrioventricular 
septal defects, simple forms of tetralogy of Fallot, arterial trunk and transposition of the great arteries. Diagnostic heart catheterization is only rarely performed for the morphologically 'simple' congenital lesions but is still performed for some of the more complex forms of congenital heart disease like the functionally univentricular heart. In most centers about $2 / 3$ of all catheterizations are interventional.

Apart from transthoracic echocardiography, the development of transesophageal echocardiography was extremely important for congenital heart disease. In the late 1980s miniaturization of transesophageal probes allowed the use of transoesophageal echocardiography (TEE) especially for monitoring surgical and interventional techniques in the operating room and the catheterization laboratory [44]. The introduction of peri-operative TEE resulted in better surgical outcomes and has had a significant impact on the number of re-operations due to residual lesions. Randolph et al. showed a major impact from peri-operative transesophageal echocardiography in up to $14 \%$ of patients [37]. Using this technique the preoperative diagnosis can be refined and the immediate postoperative result can be evaluated after cardiopulmonary bypass in the operating room before the patient is transferred to the intensive care unit. Also, the development of some of the interventional catheterisation procedures, such as device closure of atrial septal and ventricular septal defects, has certainly been facilitated by the availability of TEE in the 'cath lab' [32]. One of the limitations of the transesophageal probes is the rather big size which certainly limits their use in children $<3 \mathrm{~kg}$. Since more and more children below this weight are undergoing cardiac surgery, this has become an important issue $[3,43,45]$.

Despite the impressive technical developments in echocardiographic technology during the past 50 years, there are still important challenges which new techniques try to answer. One of these challenges is the 2D nature of echocardiography which is used to look at complex moving 3D cardiac structures. The 3D relationships between the different anatomical structures need to be reconstructed in the mind of the echocardiographer. This requires a lot of training and expertise. Therefore there is a need for a realtime 3D echocardiographic technique. Also, the techniques used to evaluate left ventricular function in adult cardiology are not easily applicable to the complex world of congenital heart disease. The sometimes complex geometry and influence of variable loading conditions (pressure and volume loading) complicate the assessment of systolic and diastolic function in children. Often a subjective 'eyeballing' technique is used to evaluate cardiac function in children. So there is a need for better quantitative techniques for the assessment of ventricular function in children. Finally, the extracardiac structures, like the central and (particularly) peripheral pulmonary arteries, the aortic arch with the cervical vessels, and the systemic and pulmonary veins can sometimes be very difficult to image using echocardiography. To view these structures in detail, use of other imaging techniques like CT and MRI are necessary.

New developments in echocardiography as well as in other forms of cardiac imaging have tried to address these shortcomings in recent years. These include intracardiac echocardiography, 3D echocardiography, new techniques to assess ventricular function like tissue Doppler techniques, new developments in cardiac magnetic resonance imaging, and new developments in cardiac multislice CT. Finally it should be realized that especially echocardiography is an operator-dependent technique which requires extensive training. Recent European developments in training requirements and accreditation in pediatric and congenital echocardiography try to address this intrinsic problem.

\section{How the face of cardiac imaging in pediatrics is changing. Recent developments in cardiac imaging}

Intracardiac echocardiography (ICE)

Intravascular ultrasound to study intracoronary vessel wall anatomy is an established technique in cardiology/vascular biology [35]. Combining the experiences of intravascular ultrasound with those of transesophageal echocardiography, the development of an intracardiac echoprobe, which can be put inside the heart to view the different cardiac structures without interference from extracardiac structures, was a logical step $[25,39]$. An intracardiac echoprobe was developed which can be introduced into the femoral vein through a 10 French introducer and advanced into the atrium (Fig. 1). From this position different intracardiac

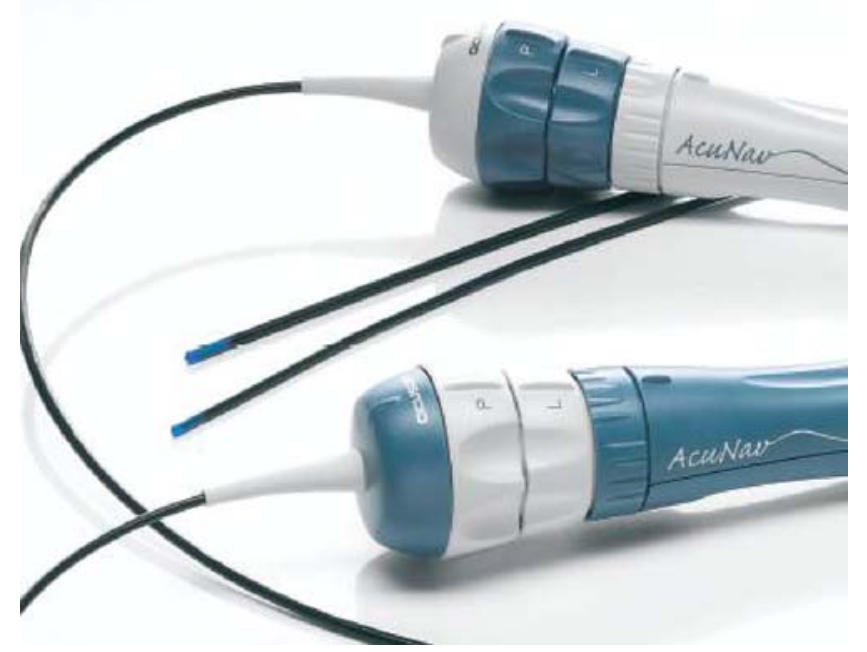

Fig. 1 Intracardiac echoprobes of $10 \mathrm{~F}$ and $8 \mathrm{~F}$ 
structures can be imaged with high resolution. The probe acquires images in two different scanning planes only and is not a 'multiplane' probe like the current transoesophageal probes. Intracardiac echocardiograhpy is mainly used for monitoring invasive cardiac procedures like closure of atrial and ventricular septal defects and patent foramen ovale $[4,5$, $8,34,36]$. The advantage is that one does not need a transesophageal probe (which causes discomfort for the patient) and an extra operator to manipulate the probe. This means that, especially in adults, the interventional procedures can be comfortably performed under local anesthesia. The disadvantage is the rather large introducer which limits its use in children and the high cost of the single-use intracardiac transducer. Recently, an $8 \mathrm{~F}$ intracardiac probe was developed [28], which is a further improvement, as the intracardiac probe is much smaller compared to the current pediatric transesophageal probes. These probes have also been used as biplane transesophageal probes for small infants. The very low profile of the probe allows a safe introduction into the oesophagus in infants below $3 \mathrm{~kg}$ [7]. Used this way, ICE probes have become popular tools to perform peri-operative TEEs in small infants undergoing cardiac surgery.

\section{Three-dimensional echocardiography}

The heart is a complex 3D structure which can be very difficult to reconstruct by $2 \mathrm{D}$ images. Therefore the development of 3D imaging was a logical but difficult step. Originally $3 \mathrm{D}$ reconstruction could be obtained from ECG-gated 2D images obtained by probes rotating on the chest of the patients [41]. This was a very cumbersome and time-consuming procedure requiring extensive off-line analysis. Moreover, the large probes did not really fit on small chests making the technique not applicable for children. It was only through the development of matrix probes, which can process ultrasound beams transmitted into the tissue in different directions, that real-time three dimensional echocardiography became technically feasible [49]. These probes contain more than 2,000 elements which allow scanning in different planes at the same time. Using these new probes, full volumetric datasets of the beating heart can be obtained which can be rotated and rapidly sliced in almost any direction to analyze cardiac anatomy (Fig. 2). In this way the 3D relationships in cardiac structures can be studied in volumetric datasets obtained within the same heartbeat. Additionally, quantitative measurements allow use of this spatial information to more reliably measure surfaces, orifices, volumes, and shape. This spatial information is useful for the assessment of congenital heart disease. Currently, reports are being published on the use of this new technique in the assessment of atrial septal defects $[2,50]$, ventricular septal defects $[1,9,51]$, atrioventricular septal defects [20, 38, 47, 52, 53], and other congenital lesions. The addition of 3D color-Doppler imaging can be helpful in assessing the mechanism of valvular regurgitation, allowing for a detailed preoperative assessment. Until recently the availability of only low frequency matrix transducers limited spatial resolution in children. The very recent release of a high frequency pediatric 3D transducer resulted in improving the spatial resolution even in small infants. Detailed 3D images of cardiac structures in even small babies can now be obtained. The time resolution is still poor and certainly the image quality and the on-line and off-line handling of the volumetric datasets could further be improved. No doubt further technical improvements will make this a standard technique in pediatric cardiac imaging. The challenge will be how this can be integrated into daily clinical practice. In 2007 a new transesophageal probe will be released allowing real-time transesophageal 3D echocardiography [17]. This will further improve peri-operative imaging.

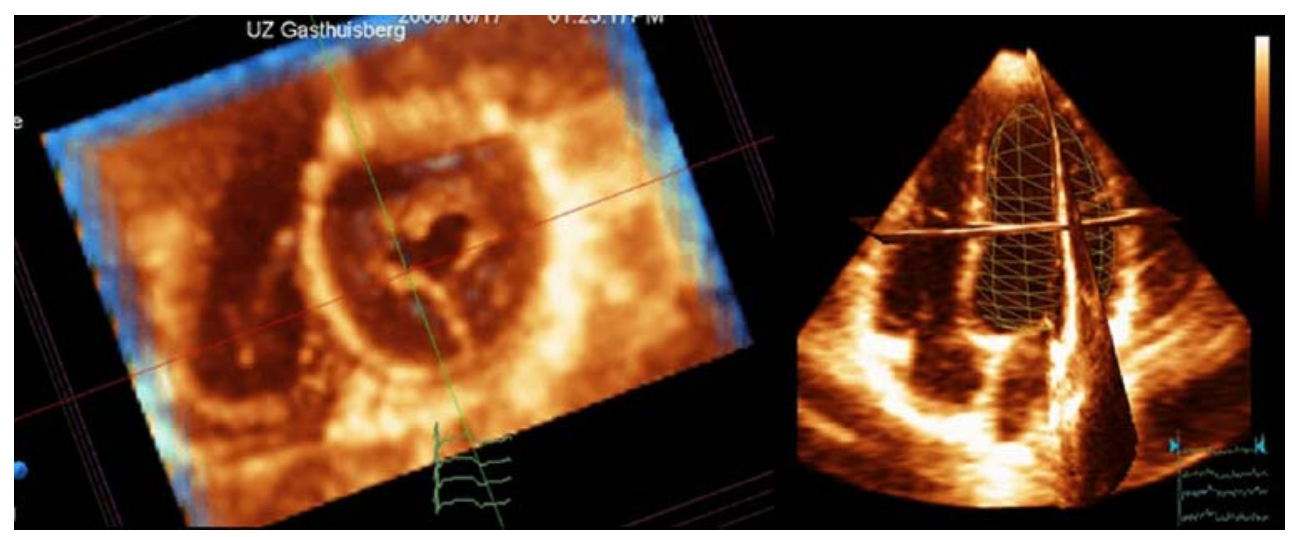

Fig. 2 Three-dimensional images. a 3D view from the left atrium on an abnormal mitral valve. b Shows how the volume and ejection fraction can be calculated based on a 3D dataset. After border detection a 3D volume of the left ventricle is calculated and represented by the 'mesh'.
This can be done throughout the cardiac cycle allowing calculation of end systolic and end diastolic left ventricular volumes. When these volumes are known, ejection fraction can be calculated 
New techniques to assess ventricular function in children

Echocardiography not only opened up the world of cardiac anatomy for noninvasive evaluation, but also allows evaluation of ventricular function. Global cardiac performance is determined by a complex interaction between intrinsic contractility, preload, afterload, and heart rate. Obviously one would like to describe intrinsic myocardial contractility, but due to the fact that a lot of parameters are influenced by loading conditions, this has turned out to become the 'holy grail' of echocardiography. Traditionally, dimensional changes or volumetric changes during the ejection phase of the cardiac cycle have been used to assess systolic ventricular function. This can be done using 1D Mmode techniques to calculate fractional shortening (left ventricular end diastolic dimension - left ventricular end systolic dimension/left ventricular end diastolic dimension) or by volumetric techniques to calculate ejection fraction (left ventricular end diastolic volume - left ventricular end systolic volume/left ventricular end diastolic volume). These techniques are especially load-sensitive and, as for the calculation of volumetric changes, geometrical assumptions are needed, so they cannot be readily applied to congenital heart disease. Another limitation is that most of the quantitative functional measurements have been designed to

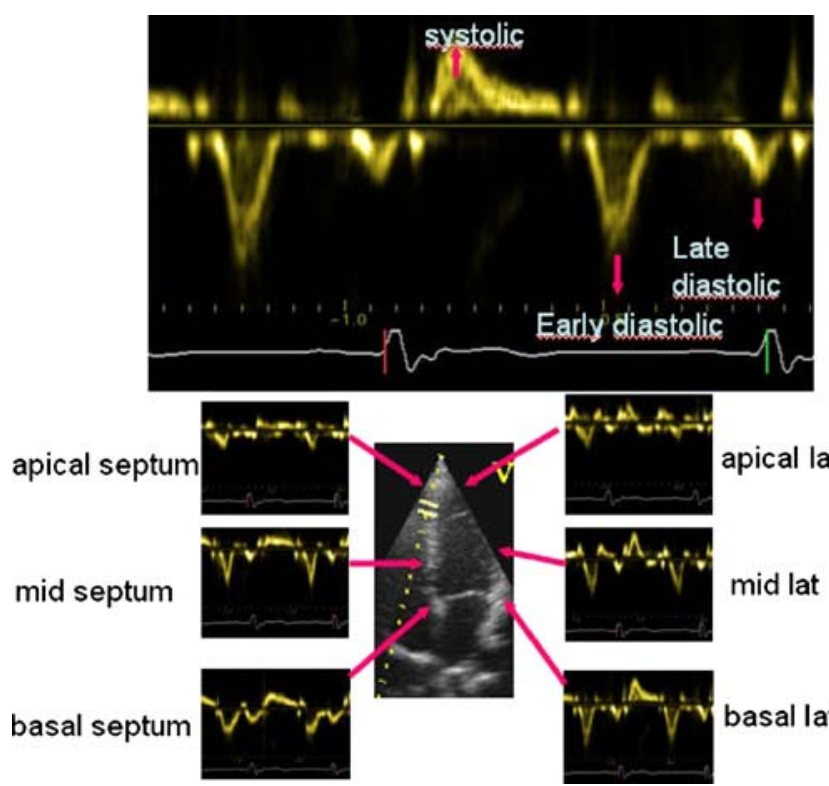

Fig. 3 Tissue Doppler velocities can be measured in different segments of the left and right ventricle. In this figure longitudinal velocities in the basal, mid, and apical segments of the interventricular septum and the left ventricular lateral wall are depicted. In the traces obtained, we can measure a peak systolic velocity as well as an early and late diastolic velocity. The systolic and diastolic velocities vary in different myocardial segments with a velocity gradient going from base to apex. The lowest velocities are measured at the apex which is relatively immobile assess left ventricular function and cannot be applied to the right ventricle which has a completely different morphology.

Recent technical developments have renewed the interest in functional assessment of patients with congenital heart disease. One of the developments is tissue Doppler echocardiography. As the myocardium is moving during the contractile cycle, velocities within the myocardium can be recorded using Doppler technology [46] (Fig. 3). By measuring these tissue Doppler velocities in different regions within the myocardium, regional myocardial function can be assessed. This technique has been applied to children with different congenital lesions, and has provided new information on both systolic, but also on diastolic function. Normal values have been established in children and have been shown to change with age [13]. This has been applied to several pediatric disorders, and especially in hypertrophic cardiomyopathy, reduced systolic and diastolic myocardial velocities were proven to be important prognostic factors [30]. The use of regional myocardial velocities is limited by the fact that the velocity of a certain myocardial segment is affected by global cardiac motion within the chest (cardiac translation) and the effect (pulling) of surrounding segments on the segment of interest (tethering). This problem can be overcome by measuring regional deformation using strain and strain rate imaging [18]. These methods look at velocity gradients within the myocardium to actually quantify regional myocardial deformation (Figs. 4 and 5). Strain rate measures the rate of deformation of a myocardial segment, and strain measures the local percentage of deformation within the same segment. This technology has been applied to pediatric cardiology to quantify regional myocardial function in different pediatric groups. It has been shown to be able to quantify right ventricular function in patients with tetralogy of Fallot [57] and after the Senning operation [14].

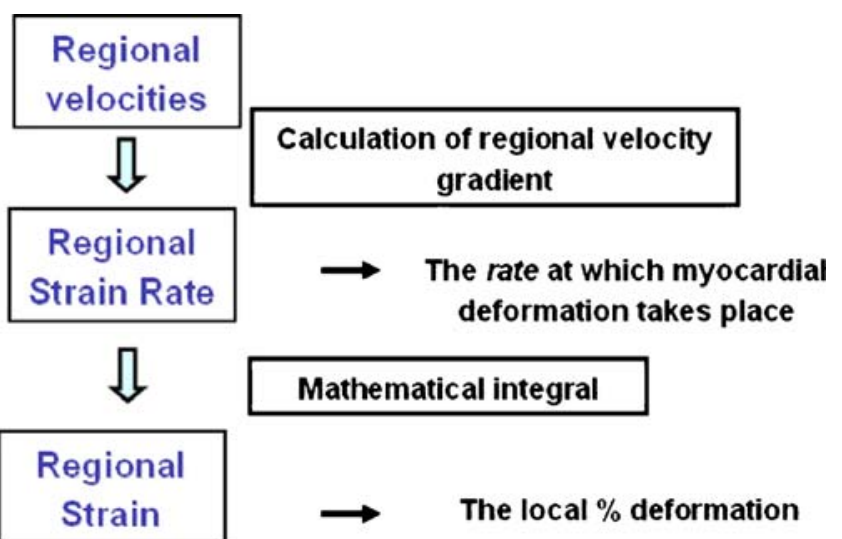

Fig. 4 Principle of strain measurements. Based on the velocity gradient from base to apex (in the longitudinal direction) or from endocardium to epicardium (in the radial direction), strain rate can be calculated. Integrating the strain rate curve in time results in a strain curve. Strain measures the percentage deformation in a segment, and strain rate measure the rate of deformation in a segment 

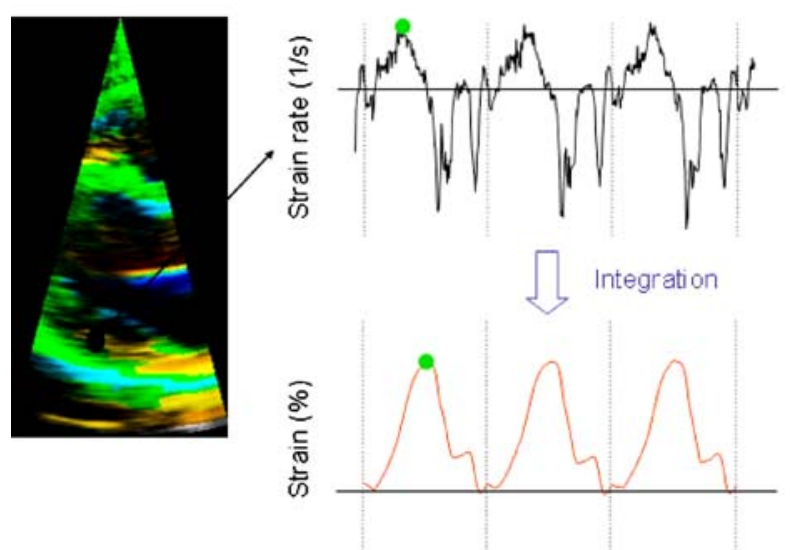

Fig. 5 This figures illustrates strain and strain rate curves obtained in the posterior wall. From these curves, peak systolic strain rate and end-systolic strain values are obtained which are used as parameters for regional cardiac function. When deformation is reduced this indicates a regional reduced cardiac performance

Moreover this technique detects subclinical myocardial dysfunction in patients receiving anthracyclines [15], patients with hypertrophic cardiomyopathy [56], and also in young patients with Duchenne muscular dystrophy [16]. This technique has the advantage of looking directly into the myocardium, but as it is looking at ejection phase indices of deformation, they are also afterload- and preload-dependent. They thus do not directly reflect intrinsic contractility but have the advantage of being more geometry-independent.

A possible solution to the load-dependency of ejectionphase parameters was suggested looking at myocardial motion during the isovolumetric contraction period. During this time period there is a velocity within the myocardium, probably related to the shape change from a more spherical ventricle to an ellipsoid shape (Fig. 6). The acceleration of this velocity seems to be a good index for intrinsic myocardial function, relatively independent of load changes [55]. This method is ideal to study contractile reserve during stress testing [54] and exercise echocardiography, and also during heart rate manipulations to study the force frequency relationship [10].

From the tissue Doppler and deformation data it has become obvious that the cardiac contraction pattern in different cardiac segments in patients with congenital or acquired heart disease can be extremely dyssynchronous reducing the mechanical efficiency of the global contraction. Restoring the synchronicity between the different cardiac segments by biventricular pacing techniques can in some patients improve cardiac function. This has recently been applied in patients with congenital heart disease with very promising results $[11,21]$.

Further study is needed to look at the relationship between deformation, loading, and geometry. This will require the combination of 3D techniques, myocardial imaging, and computational modelling of cardiac mechanics.

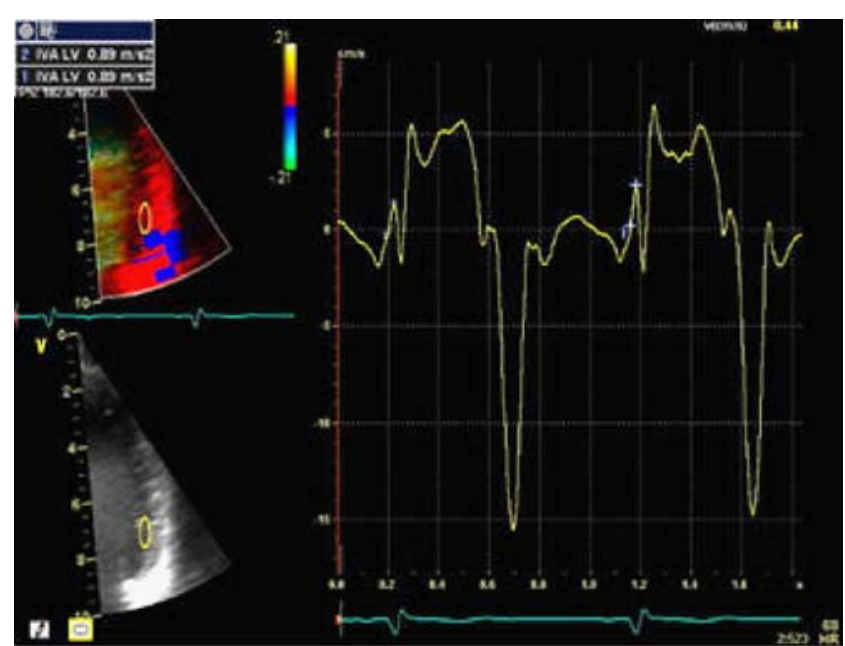

\section{$\mathrm{IVA}=\delta \mathrm{v} / \delta \mathrm{t}$}

Fig. 6 Isovolumetric acceleration. During the isovolumetric contraction period, there is a velocity spike in the tracing. The acceleration of this velocity spike is a good parameter for intrinsic contractility

New developments in cardiac magnetic resonance imaging (MRI)

Cardiac magnetic resonance imaging (MRI) is rapidly developing and currently is becoming increasingly accepted as an important imaging tool in pediatric cardiology. The indications are situated in these areas where echocardiography cannot answer the clinical questions. A first common indication for the use of cardiac MRI is for better visualisation of extracardiac anatomic structures including the pulmonary arteries with the distal branches, the aorta, the pulmonary veins, and the systemic veins $[22,27]$. If there is any doubt about these structures which can be difficult/impossible to visualize using echocardiography because of interposition of the lungs, MRI is a good alternative to cardiac catheterisation with a high spatial resolution. Even smaller vessels like the coronary arteries can nicely be displayed using cardiac MRI. This can be applied in the evaluation of coronary arteries after Kawasaki disease [29] or to evaluate coronary anatomy after the arterial switch operation [48].

Cardiac MRI has the advantage of being a volumetric technique allowing 3D reconstructions. This is advantageous for the evaluation of congenital heart disease. Complex intracardiac anatomy can be displayed, but for describing intracardiac anatomy, echocardiography is probably still the preferred technique. With cardiac MRI not only anatomy but also blood flow and ventricular function can be studied. Blood flow measurements allow the quantification of left-to-right shunts and the quantification valve regurgitation [24]. This has been applied to patients after tetralogy of Fallot repair where pulmonary regurgitation is one of the important residual lesions which can be difficult to evaluate using echocardiography [23]. Due to its 
volumetric measurements, cardiac MRI has become the golden standard for the quantification of ventricular mass and volumes of both left and right ventricles. These measurements can be applied to quantify ejection fraction and ventricular performance. Currently, it has become the technique of choice to study right ventricular function in patients after tetralogy of Fallot repair and in patients with systemic right ventricles, e.g., after a Senning or Mustard operation for transposition of the great arteries. Ventricular mechanics can be assessed using myocardial tagging imaging which allows 3D assessment of ventricular mechanics [31]. This has been used in patients with complex congenital heart disease. The major drawback of this technique is that it requires complicated postprocessing, turning it into a specialized research tool.

Finally there is hope that in the future cardiac interventions in congenital heart disease can be performed using MRI [40]. Currently X-MR suites are being used for combining fluoroscopy and MR to guide complex interventions like stent implantation in difficult pulmonary artery stenosis. Currently it is still not possible to use MRI only to guide interventions. This will require new technical developments like catheters and devices which can be visualized in the MR scanner. Another issue is the temporal resolution of the technique which is currently still a limitation.

Multislice computed tomography (CT) in pediatric cardiology

During recent years CT technology has evolved extremely quickly through the development of the multidetector CT scanners. The development of 16-, 32-, 64, and 128detector CT technology allowed extremely fast acquisition with very high spatial resolution. For anatomical description, this technology can be considered as an alternative to MRI for visualization and 3D reconstruction of extracardiac anatomical structures like the pulmonary arteries, the aorta, the pulmonary veins, and even smaller vessels like the coronary arteries [26, 27]. For this last indication, cardiac $\mathrm{CT}$ is more and more often considered to be an alternative to coronary angiography in the detection of coronary artery disease. Thus, it has also been used in pediatric cardiology in conditions where imaging of the coronary arteries is important. Also for imaging vascular rings and slings cardiac CT could be a valuable alternative to both cardiac catherization as well as cardiac MRI. Compared to cardiac MRI, the short acquisition times of multislice CT are a great advantage obviating the need for sedation or general anaesthesia in younger patients. A full MR study easily takes 30-60 minutes while a multidetector CT study can be performed in a few seconds. The important disadvantage and concern is the radiation exposure associated with the multiple detectors. As the number of detectors is increasing, so is the radiation dose. This is an issue which must be resolved as the long-term effects of radiation exposure in children are uncertain. Hopefully, technical improvements and new scanning protocols will resolve this issue.

European standards for training and accreditation in pediatric echocardiography and cardiac MRI

Imaging techniques are changing very quickly and this is a real challenge for the users of this technology. Training and, afterwards, maintaining competence has become a real challenge. Due to the relatively small size of most pediatric cardiology programs in Europe, there are few established training programs focussing on the different imaging modalities. In Europe most pediatric cardiologists are trained as allaround specialists with no subspecialty training in cardiac imaging. In order to guide training in cardiac imaging the Association for European Pediatric Cardiology published training guidelines for pediatric echocardiography and cardiac MRI $[19,33]$. In addition a European accreditation process was developed by the AEPC in collaboration with the European Association of Echocardiography (EAE). This process consists of a theoretical examination which took place for the first time in 2006 during the Euroecho 10 meeting in Prague, and a practical part which requires the submission of 750 written reports. The first 14 candidates successfully passed the theoretical test. The introduction of individual accreditation will be followed by accreditation of echocardiography laboratories in the near future. In this way quality standards are set for the practice of pediatric echocardiography in Europe. In this way it is hoped to guarantee high quality diagnostics to children with congenital and acquired heart disease.

\section{References}

1. Acar P, Abadir S, Aggoun Y (2007) Transcatheter closure of perimembranous ventricular septal defects with Amplatzer occluder assessed by real-time three-dimensional echocardiography. Eur J Echocardiogr 8:110-115

2. Acar P, Roux D, Dulac Y, Rouge P, Aggoun Y (2003) Transthoracic three-dimensional echocardiography prior to closure of atrial septal defects in children. Cardiol Young 13:58-63

3. Ades A, Johnson BA, Berger S (2005) Management of low birth weight infants with congenital heart disease. Clin Perinatol 32:999-1015

4. Bartel T, Konorza T, Arjumand J, Ebradlidze T, Eggebrecht H, Caspari G, Neudorf U, Erbel R (2003) Intracardiac echocardiography is superior to conventional monitoring for guiding device closure of interatrial communications. Circulation 107:795-797

5. Bartel T, Konorza T, Neudorf U, Ebralize T, Eggebrecht H, Gutersohn A, Erbel R (2005) Intracardiac echocardiography: an ideal guiding tool for device closure of interatrial communications. Eur J Echocardiogr 6:92-96

6. Bennett D, Marcus R, Stokes M (2005) Incidents and complications during pediatric cardiac catheterization. Paediatr Anaesth 15:1083-1088 
7. Bruce CJ, O'Leary P, Hagler DJ, Seward JB, Cabalka AK (2002) Miniaturized transesophageal echocardiography in newborn infants. J Am Soc Echocardiogr 15:791-797

8. Cao QL, Zabal C, Koenig P, Sandhu S, Hijazi ZM (2005) Initial clinical experience with intracardiac echocardiography in guiding transcatheter closure of perimembranous ventricular septal defects: feasibility and comparison with transesophageal echocardiography. Catheter Cardiovasc Interv 66:258-267

9. Chen FL, Hsiung MC, Nanda N, Hsieh KS, Chou MC (2006) Real time three-dimensional echocardiography in assessing ventricular septal defects: an echocardiographic-surgical correlative study. Echocardiography 23:562-568

10. Cheung MM, Smallhorn JF, Vogel M, Van Arsdell G, Redington AN (2006) Disruption of the ventricular myocardial forcefrequency relationship after cardiac surgery in children: noninvasive assessment by means of tissue Doppler imaging. J Thorac Cardiovasc Surg 131:625-631

11. Dubin AM, Janousek J, Rhee E, Strieper MJ, Cecchin F, Law IH, Shannon KM, Temple J, Rosenthal E, Zimmerman FJ, Davis A, Karpawich PP, Al Ahmad A, Vetter VL, Kertesz NJ, Shah M, Snyder C, Stephenson E, Emmel M, Sanatani S, Kanter R, Batra A, Collins KK (2005) Resynchronization therapy in pediatric and congenital heart disease patients: an international multicenter study. J Am Coll Cardiol 46:2277-2283

12. Edler I, Lindstrom K (2004) The history of echocardiography. Ultrasound Med Biol 30:1565-1644

13. Eidem BW, McMahon CJ, Cohen RR, Wu J, Finkelshteyn I, Kovalchin JP, Ayres NA, Bezold LI, O'Brian Smith E, Pignatelli RH (2004) Impact of cardiac growth on Doppler tissue imaging velocities: a study in healthy children. J Am Soc Echocardiogr 17:212-221

14. Eyskens B, Weidemann F, Kowalski M, Bogaert J, Dymarkowski S, Bijnens B, Gewillig M, Sutherland G, Mertens L (2004) Regional right and left ventricular function after the Senning operation: an ultrasonic study of strain rate and strain. Cardiol Young 14:255-264

15. Ganame J, Claus P, Eyskens B, Uyttebroeck A, Renard M, D'Hooge J, Gewillig M, Bijnens B, Sutherland G, Mertens L (2007) Acute cardiac functional changes after subsequent antracycline infusions in children. Am J Cardiol 99:974-977

16. Giatrakos N, Kinali M, Stephens D, Dawson D, Muntoni F, Nihoyannopoulos P (2006) Cardiac tissue velocities and strain rate in the early detection of myocardial dysfunction of asymptomatic boys with Duchenne's muscular dystrophy: relationship to clinical outcome. Heart 92:840-842

17. Handke M, Heinrichs G, Moser U, Hirt F, Margadant F, Gattiker F, Bode C, Geibel A (2006) Transesophageal real-time threedimensional echocardiography methods and initial in vitro and human in vivo studies. J Am Coll Cardiol 48:2070-2076

18. Hatle L, Sutherland GR (2000) Regional myocardial function-a new approach. Eur Heart J 21:1337-1357

19. Helbing WA, Mertens L, Sieverding L (2006) Recommendations from the Association for European Paediatric Cardiology for training in congenital cardiovascular magnetic resonance imaging. Cardiol Young 16:410-412

20. Hlavacek AM, Crawford FA Jr, Chessa KS, Shirali GS (2006) Real-time three-dimensional echocardiography is useful in the evaluation of patients with atrioventricular septal defects. Echocardiography 23:225-231

21. Janousek J, Tomek V, Chaloupecky VA, Reich O, Gebauer RA, Kautzner J, Hucin B (2004) Cardiac resynchronization therapy: a novel adjunct to the treatment and prevention of systemic right ventricular failure. J Am Coll Cardiol 44:1927-1931

22. Johnson TR, Goldmuntz E, McDonald-McGinn DM, Zackai EH, Fogel MA (2005) Cardiac magnetic resonance imaging for accurate diagnosis of aortic arch anomalies in patients with 22q11.2 deletion. Am J Cardiol 96:1726-1730
23. Knauth AL, Gauvreau K, Powell AJ, Landzberg MJ, Walsh EP, Lock JE, Delnido PJ, Geva T (2006) Ventricular size and function assessed by cardiac MRI predict major adverse clinical outcomes late after tetralogy of fallot repair. Heart (Published Online November 29, 2006). DOI 10.1136/hrt.2006.104745

24. Korperich H, Gieseke J, Barth P, Hoogeveen R, Esdorn H, Peterschroder A, Meyer H, Beerbaum P (2004) Flow volume and shunt quantification in pediatric congenital heart disease by realtime magnetic resonance velocity mapping: a validation study. Circulation 109:1987-1993

25. Kort S (2006) Intracardiac echocardiography: evolution, recent advances, and current applications. J Am Soc Echocardiogr 19:1192-1201

26. Lambert V, Sigal-Cinqualbre A, Belli E, Planche C, Roussin R, Serraf A, Bruniaux J, Angel C, Paul JF (2005) Preoperative and postoperative evaluation of airways compression in pediatric patients with 3dimensional multislice computed tomographic scanning: effect on surgical management. J Thorac Cardiovasc Surg 129:1111-1118

27. Ley S, Zaporozhan J, Arnold R, Eichhorn J, Schenk JP, Ulmer H, Kreitner KF, Kauczor HU (2007) Preoperative assessment and follow-up of congenital abnormalities of the pulmonary arteries using CT and MRI. Eur Radiol 17:151-162

28. Luxenberg DM, Silvestry FE, Herrmann HC, Cao QL, Rohatgi S, Hijazi ZM (2005) Use of a new 8 French intracardiac echocardiographic catheter to guide device closure of atrial septal defects and patent foramen ovale in small children and adults: initial clinical experience. J Invasive Cardiol 17:540-545

29. Mavrogeni S, Papadopoulos G, Douskou M, Kaklis S, Seimenis I, Varlamis G, Karanasios E, Krikos X, Giannoulia A, Cokkinos DV (2006) Magnetic resonance angiography, function and viability evaluation in patients with Kawasaki disease. J Cardiovasc Magn Reson 8:493-498

30. McMahon CJ, Nagueh SF, Pignatelli RH, Denfield SW, Dreyer WJ, Price JF, Clunie S, Bezold LI, Hays AL, Towbin JA, Eidem BW (2004) Characterization of left ventricular diastolic function by tissue Doppler imaging and clinical status in children with hypertrophic cardiomyopathy. Circulation 109:1756-1762

31. Menteer J, Weinberg PM, Fogel MA (2005) Quantifying regional right ventricular function in tetralogy of Fallot. J Cardiovasc Magn Reson 7:753-761

32. Mertens L, Budts W (2004) New developments in the transcatheter treatment of congenital heart disease. Curr Opin Anaesthesiol 17:329-334

33. Mertens L, Helbing W, Sieverding L, Daniels O (2005) Guidelines from the Association for European Paediatric Cardiology: standards for training in paediatric echocardiography. Cardiol Young $15: 441-442$

34. Mullen MJ, Dias BF, Walker F, Siu SC, Benson LN, McLaughlin PR (2003) Intracardiac echocardiography guided device closure of atrial septal defects. J Am Coll Cardiol 41:285-292

35. Nicholls SJ, Tuzcu EM, Sipahi I, Schoenhagen P, Nissen SE (2006) Intravascular ultrasound in cardiovascular medicine. Circulation 114:e55-e59

36. O'Leary PW (2002) Intracardiac echocardiography in congenital heart disease: are we ready to begin the fantastic voyage? Pediatr Cardiol 23:286-291

37. Randolph GR, Hagler DJ, Connolly HM, Dearani JA, Puga FJ, Danielson GK, Abel MD, Pankratz VS, O'Leary PW (2002) Intraoperative transesophageal echocardiography during surgery for congenital heart defects. J Thorac Cardiovasc Surg 124:1176-1182

38. Rawlins DB, Austin C, Simpson JM (2006) Live threedimensional paediatric intraoperative epicardial echocardiography as a guide to surgical repair of atrioventricular valves. Cardiol Young 16:34-39

39. Ren JF, Schwartzman D, Callans DJ, Brode SE, Gottlieb CD, Marchlinski FE (1999) Intracardiac echocardiography (9 MHz) in 
humans: methods, imaging views and clinical utility. Ultrasound Med Biol 25:1077-1086

40. Rickers C, Kraitchman D, Fischer G, Kramer HH, Wilke N, Jerosch-Herold M (2005) Cardiovascular interventional MR imaging: a new road for therapy and repair in the heart. Magn Reson Imaging Clin N Am 13:465-479

41. Roelandt J, Salustri A, Mumm B, Vletter W (1995) Precordial threedimensional echocardiography with a rotational imaging probe: methods and initial clinical experience. Echocardiography 12:243-252

42. Roelandt JR (2003) The 50th anniversary of echocardiography: are we at the dawn of a new era? Eur J Echocardiogr 4:233-236

43. Roussin R, Belli E, Bruniaux J, Demontoux S, Touchot A, Planche C, Serraf A (2007) Surgery for transposition of the great arteries in neonates weighing less than 2,000 grams: a consecutive series of 25 patients. Ann Thorac Surg 83:173-178

44. Stumper O, Kaulitz R, Elzenga NJ, Bom N, Roelandt JR, Hess J, Sutherland GR (1991) The value of transesophageal echocardiography in children with congenital heart disease. J Am Soc Echocardiogr 4:164-176

45. Sudarshan CD, Cochrane AD, Jun ZH, Soto R, Brizard CP (2006) Repair of coarctation of the aorta in infants weighing less than 2 kilograms. Ann Thorac Surg 82:158-163

46. Sutherland GR, Stewart MJ, Groundstroem KW, Moran CM, Fleming A, Guell-Peris FJ, Riemersma RA, Fenn LN, Fox KA, McDicken WN (1994) Color Doppler myocardial imaging: a new technique for the assessment of myocardial function. J Am Soc Echocardiogr 7:441-458

47. Takahashi K, Guerra V, Roman KS, Nii M, Redington A, Smallhorn JF (2006) Three-dimensional echocardiography improves the understanding of the mechanisms and site of left atrioventricular valve regurgitation in atrioventricular septal defect. J Am Soc Echocardiogr 19:1502-1510

48. Taylor AM, Dymarkowski S, Hamaekers P, Razavi R, Gewillig M, Mertens L, Bogaert J (2005) MR coronary angiography and late-enhancement myocardial MR in children who underwent arterial switch surgery for transposition of great arteries. Radiology $234: 542-547$

49. van den Bosch AE, Krenning BJ, Roelandt JR (2005) Threedimensional echocardiography. Minerva Cardioangiol 53:177-184
50. van den Bosch AE, Ten Harkel DJ, McGhie JS, Roos-Hesselink JW, Simoons ML, Bogers AJ, Meijboom FJ (2006) Characterization of atrial septal defect assessed by real-time 3-dimensional echocardiography. J Am Soc Echocardiogr 19:815-821

51. van den Bosch AE, Ten Harkel DJ, McGhie JS, Roos-Hesselink JW, Simoons ML, Bogers AJ, Meijboom FJ (2006) Feasibility and accuracy of real-time 3-dimensional echocardiographic assessment of ventricular septal defects. J Am Soc Echocardiogr 19:7-13

52. van den Bosch AE, Ten Harkel DJ, McGhie JS, Roos-Hesselink JW, Simoons ML, Bogers AJ, Meijboom FJ (2006) Surgical validation of real-time transthoracic $3 \mathrm{D}$ echocardiographic assessment of atrioventricular septal defects. Int J Cardiol 112:213-218

53. van den Bosch AE, van Dijk VF, McGhie JS, Bogers AJ, RoosHesselink JW, Simoons ML, Meijboom FJ (2006) Real-time transthoracic three-dimensional echocardiography provides additional information of left-sided AV valve morphology after AVSD repair. Int J Cardiol 106:360-364

54. Vogel M, Derrick G, White PA, Cullen S, Aichner H, Deanfield J, Redington AN (2004) Systemic ventricular function in patients with transposition of the great arteries after atrial repair: a tissue Doppler and conductance catheter study. J Am Coll Cardiol 43:100-106

55. Vogel M, Schmidt MR, Kristiansen SB, Cheung M, White PA, Sorensen K, Redington AN (2002) Validation of myocardial acceleration during isovolumic contraction as a novel noninvasive index of right ventricular contractility: comparison with ventricular pressure-volume relations in an animal model. Circulation 105:1693-1699

56. Weidemann F, Eyskens B, Mertens L, Di Salvo G, Strotmann J, Buyse G, Claus P, D’Hooge J, Bijnens B, Gewillig M, Sutherland GR (2003) Quantification of regional right and left ventricular function by ultrasonic strain rate and strain indexes in Friedreich's ataxia. Am J Cardiol 91:622-626

57. Weidemann F, Eyskens B, Mertens L, Dommke C, Kowalski M, Simmons L, Claus P, Bijnens B, Gewillig M, Hatle L, Sutherland GR (2002) Quantification of regional right and left ventricular function by ultrasonic strain rate and strain indexes after surgical repair of tetralogy of Fallot. Am J Cardiol 90:133-138 